\title{
Gravidez Ectópica Tubária Bilateral: Relato de Caso
}

\author{
A Bilateral Fallopian Tube Pregnancy: A Case Report
}

Assis Oberdan Posser, Zélia Berenice Rocha Posser

Cristina Roveré Gehling, Gilberto Ortiz, Bianca Avancini

\begin{abstract}
RESUM0
Gestação ectópica bilateral é a forma mais rara de gestação gemelar, considerando que menos de 250 casos foram relatados na literatura. Nosso caso preenche o critério diagnóstico determinado por Norris ${ }^{9}$ que requer a demonstração de vilos coriônicos em cada tuba de uterina. Relatamos o caso de uma mulher multipara de 36 anos de idade que desenvolveu um episódio de abdômen agudo hemorrágico. Uma laparotomia realizada com anestesia geral revelou hemoperitônio de 1,8 litros; ambas tubas uterinas aumentadas de volume e com laceração de suas paredes e presença de dois embriões medindo 2,7 e 3,0 cm de comprimento, livres no sangue intra-abdominal. Apresentamos uma revisão da literatura a respeito da gestação ectópica bilateral.
\end{abstract}

PALAVRAS-CHAVE: Tubas. Gravidez ectópica. Gemelaridade. Laparotomia. Abdômen agudo.

\section{Introdução}

A gestação ectópica bilateral (GEB) é uma forma de gestação biovular incomum, em que a implantação e o desenvolvimento dos ovos fertilizados ocorre fora da cavidade uterina, nas tubas. Na literatura mundial há aproximadamente 250 casos relatados. A incidência da GEB é estimada como sendo de 1 caso para 725 a 1.580 gestações ectópicas, ou de aproximadamente, 1 caso para 200.000 gestações intra-uterinas ${ }^{1,3,5,6,11,13}$.

Serviço de Residência em Ginecologia e Obstetrícia do Hospital Nossa Senhora da Conceição - Porto Alegre - RS

Correspondência:

Assis Oberdan Posser

Rua Paulo Blaschke, $\mathrm{n}^{\circ} 515$ - Jardim Planalto

CEP: 91.225 - Porto Alegre - RS - Fone: (051) 340-50-90
Na evolução da GEB poderemos encontrar: duas gestações de mesma idade, ou de diferentes idades, ambas em evolução; duas gestações, sendo que uma com desenvolvimento regular e outra com interrupção ou ainda, duas gestações, ambas com interrupção no seu desenvolvimento.

$\mathrm{Na}$ prenhez ectópica gemelar com envolvimento tubário há diversas formas de combinações e de sítios de implantação. Assim poderemos ter ${ }^{9-11}$ :

1. uma gravidez ectópica com uma gravidez única intra-uterina

2. uma gravidez ectópica com uma gravidez dupla intra-uterina

3. uma gestação ectópica bilateral contemporânea ou não

4. gestação ectópica múltiplas na mesma tuba

5. uma gestação ectópica tubária e em outro sítio 
de localização (ovariana, intraligamentar, abdominal, etc.).

A GEB tubária é a forma mais rara de gestação gemelar, seguindo-se em freqüência pela gestação ectópica múltipla na mesma tuba e pela gestação simultânea tubária e intra-uterina ${ }^{3,7}$.

Fishback em 1939, propôs como critério diagnóstico para a GEB a demonstração de tecido fetal, placentário ou de ambos em cada tuba ${ }^{4,6,7}$. Já Norris em 1953, simplificou este critério exigindo apenas a demonstração de vilosidades coriônicas em cada tuba uterina ${ }^{1-3,6,9,12,13}$.

Admitem-se como fatores etiopatogênicos os mesmos causadores da prenhez ectópica unilateral, sendo os básicos ${ }^{8}$ : alteração anatômica das tubas uterinas causada pela infecção, trauma ou cirurgia; desbalanço hormonal, observado nos casos de gestação ectópica após o uso da pílula do "dia seguinte”, dos indutores da ovulação, DIUs com progesterona, na idade materna superior a 35 anos, etc.; os defeitos inerentes do ovo fertilizado (caso de ovos imaturos ovulados prematuramente ou tardiamente) com tendência a se implantarem antes de chegar ao útero; e as técnicas de fertilização "in vitro" com transferência de embriões.

A taxa de mortalidade para a gestação ectópica situa-se em torno de 0.8 por 1.000 casos.

É feito a seguir, relato de um caso de gestação ectópica tubária bilateral embrionada rota, ocorrido no Hospital Nossa Senhora da Conceição de Porto Alegre, no dia 29.05.97.

\section{Relato do Caso}

Paciente (ILT) com 36a, branca, Gesta IV Para IV e com história negativa para DIP, cirurgia prévia ou uso de medicações nos seis meses anteriores ao evento atual. Procurou a urgência ginecológica em razão da dor importante no baixo ventre, com irradiação para a região lombo-sacra e ombros, acompanhada de náuseas, vômitos e tonturas. Importante referir que 10 dias antes, a paciente havia apresentado quadro abdominal semelhante, porém de menor intensidade, sendo medicada em outro serviço com analgésicos e repouso.

A DUM era de 28.03.97 (9,1 semanas de idade menstrual) e apresentava um título de gonadotropina coriônica de $7.200 \mathrm{mU} / \mathrm{ml}$ do dia 23.05.97.

Ao exame clínico mostrava palidez mucocutânea importante, hipotensão $(60 \times 40$ $\mathrm{mmHg}$, dor, distensão e defesa abdominal, com sinais de irritação peritoneal.

No exame ginecológico constatou-se sangramento vaginal escuro, amolecimento do colo uterino, útero globoso (8-9 semanas) e massa anexial esquerda de consistência elástica de 8-9 $\mathrm{cm}$ muito dolorosa ao toque vaginal. A culdocentese foi positiva em $15 \mathrm{ml}$ de sangue escuro.

O diagnóstico pré-operatório foi de gestação ectópica rota, sendo encaminhada para laparotomia.

Os achados cirúrgicos transoperatórios foram:

Presença de aproximadamente $1.800 \mathrm{ml} \mathrm{de}$ sangue livre e coágulos na cavidade abdominal. Ambas tubas uterinas estavam amolecidas, muito aumentadas de volume e com sinais evidentes de laceração em suas regiões ampolares.

A tuba uterina esquerda apresentava-se aderida ao útero, FSV e ao epiplon e ao realizar-se manobras para a liberação do anexo encontrou-se em meio a coágulos, embrião que media $2,7 \mathrm{~cm}$ no seu maior eixo (Figura 1).

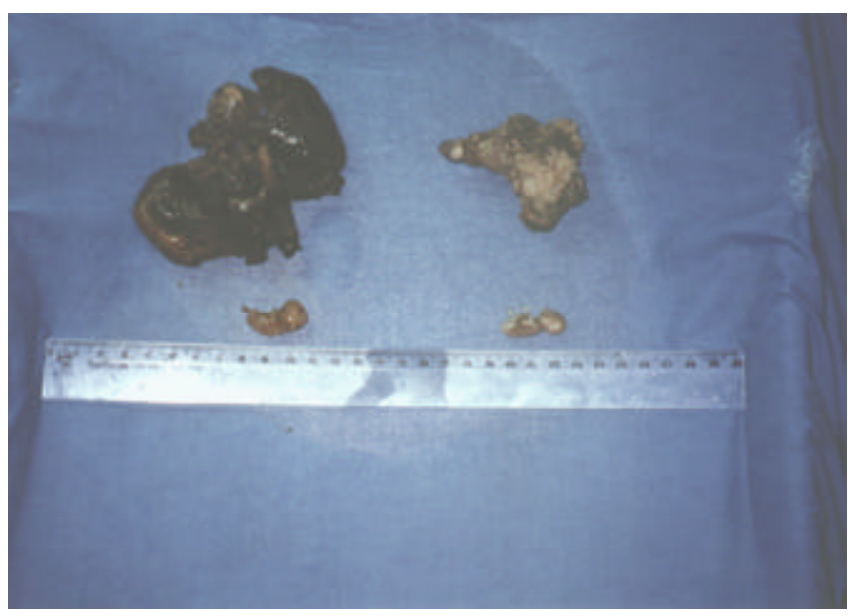

Figura 1 - Tubas uterinas esquerda e direita com respectivos embriões $(2,7$ e 3,0 cm).

A tuba uterina direita encontrava-se aumentada de volume e com sangramento ativo pela laceração de sua região ampolar. Outro embrião medindo $3.0 \mathrm{~cm}$ no seu eixo craniocaudal, foi encontrado livre em meio ao sangue (Figura 1).

O exame macroscópico das tubas uterinas e a presença dos embriões sugeriram o diagnóstico transoperatório de GEB embrionada rota, que foi confirmada pelo exame anatomopatológico, segundo os critérios de Fishback $^{4}$ e Norris ${ }^{9}$. O procedimento cirúrgico realizado foi a salpingectomia bilateral total.

O exame anatomopatológico das tubas uterinas demonstrou, tuba uterina direita aumentada de volume, medindo $7.0 \times 3.0 \times 3.0 \mathrm{~cm}$ e tuba uterina esquerda medindo $10.0 \times 2.5 \times 2.5$ $\mathrm{cm}$. Externamente apresentavam-se de cor pardo- 
escura, com paredes laceradas e acompanhavam dois embriões macerados medindo 2.7 e $3.0 \mathrm{~cm}$.

A microscopia dos cortes histológicos mostrava tubas uterinas exibindo luzes ocupadas e dilatadas por vilos coriais e tecido trofoblástico com extrema penetração na camada muscular e serosa com hemorragia recente.

O diagnóstico histopatológico foi de gestação tubária bilateral embrionada rota, com idade gestacional de 56 dias, segundo O'Rahilly.

A alta hospitalar da paciente se deu no $3^{\circ}$ dia pós-operatório em boas condições clínicas.

\section{Discussão}

Apesar dos avanços no diagnóstico precoce terem levado a uma diminuição na taxa de mortalidade e de os tratamentos laparoscópicos e cirúrgicos terem possibilitado a obtenção de melhores resultados, a gestação ectópica permanece como causa importante de mortalidade, sendo responsável por um número considerável de casos de infertilidade e de recidiva ectópica.

Desde o $1^{\circ}$ relato de GEB feito por Bledsoe em 1918, cerca de 250 novos casos foram relatados ${ }^{2,6,12,13}$, quer sejam como resultado esporádico de ciclos naturais, quer sejam de ciclos induzidos para fertilização.

Nas últimas três décadas, tem ocorrido quase que um surto epidêmico de gestação ectópica, com aumento aproximado de cinco vezes, quando comparado com taxas de 1970 nos EUA. Isto se deve basicamente à maior incidência da DIP, ao uso mais liberal do DIU, às microcirurgias sobre as tubas e à fertilização "in vitro". Fatores estes que segundo Foster et al. ${ }^{5}$, serão responsáveis futuramente pela maior incidência da GEB.

A etiologia da gestação ectópica gemelar não é de todo conhecida, porém admite-se como causadores os mesmos mecanismos responsáveis pela gestação intra-uterina ${ }^{3,11,13}$. Assim teríamos: - mecanismo de superfetação, em que a gestação gemelar ocorreria por fertilização de um ovo, durante uma gestação já em curso

- mecanismo de superfertilização, quando haveria a fertilização de dois ovos ao mesmo tempo ou dentro de um curto espaço de tempo.

No relato atual, não se evidenciaram fatores etiológicos que explicassem "per se" a prenhez ectópica. A multiparidade e a idade da paciente, segundo alguns autores, seriam fatores de risco, sendo a GEB encontrada em $85 \%$ dos casos na multípara e em apenas $15 \%$ dos casos na primipara $^{3,12}$.

Caso utilizássemos o critério ultra- sonográfico da medida do comprimento cabeçanádegas (CCN), para o cálculo da idade gestacional e transpondo-o para a medida dos embriões $(2,7 \mathrm{e}$ $3,0 \mathrm{~cm})$, teríamos respectivamente uma idade menstrual, segundo Hadlock, de 9,5 e 9,9 semanas o que sugere a possibilidade de ter ocorrido uma GEB após um mesmo ciclo ovulatório, por possível mecanismo de superfertilização.

O comprimento de $3 \mathrm{~mm}$ a mais de um dos embriões, poderia ser explicado pela interrupção posterior da gestação tubária direita, que apresentava-se com sinais de ruptura recente.

O diagnóstico da gestação ectópica é pouco previsível apenas pela clínica e mesmo com a ajuda do $\beta$-hCG e do ultra-som, a grande maioria dos casos ainda é de diagnóstico na urgência, quando instalado o abdome agudo por hemoperitônio.

A culdocentese apesar de dolorosa e pouco especifica quanto à etiologia do sangramento, ainda é método diagnóstico importante, com taxas de positividade entre 87 a $95 \%$ dos casos, justificandose na urgência ${ }^{3,8}$.

O uso criterioso do ultra-som endovaginal, com mapeamento do fluxo a cores, assim como do estudo doppler das áres de interesse, permitirá que se faça em muitos casos, diagnóstico precoce da gestação ectópica antes da ruptura tubária.

$\mathrm{O}$ exame contralateral das tubas uterinas deverá ser realizado sistematicamente pela possibilidade ainda que remota de $\mathrm{GEB}^{1,3,10,13}$.

\section{Agradecimento}

Ao Dr. Eduardo Lahude Lima pela análise histopatológica do material.

\section{SUMMARY}

Bilateral ectopic pregnancy is the most unusual twin gestation considering that less than 250 cases have been reported in the literature. Our case fulfills the diagnostic criterion determined by Norris ${ }^{9}$ which requires demonstration of chorionic villi in each fallopian tube. We report the case of a 36-year-old multiparous woman who had an hemorrhagic acute abdomen. A laparotomy performed under general anesthesia revealed hemoperitoneum of 1.8 liters and both swelled tubes with laceration of their walls, besides two embryos with 2,7 and $3,0 \mathrm{~cm}$ in length free in the intra-abdominal blood. A literature review on bilateral ectopic pregnancy is presented.

KEY WORDS: Tubes. Ectopic pregnancy. Twin gestation. Laparotomy. 


\section{Referências}

1. Abdalla AE, Alcântara AM, Bombini VC, Lopes RD. Prenhez ectópica bilateral. Rev Bras Ginecol Obst 1993; 15: 201-2.

2. Abramovici D. Morfesis FA, Ally S, Bathija NR. Bilateral ectopic pregnancy. A case report. J KY Med Assoc 1995; 93:295.

3. Clark SL, Aryasingha JC. Simultaneous bilateral tubal pregnancy. A case report. J Reprod Med 1983; 28:227-9.

4. Fishback HR. Bilateral simultaneous tubal pregnancy. Am J Obstet Gynecol 1939; 37:1035-7.

5. Foster HM, Lakshin AS, Taylor WF. Bilateral tubal pregnancy with vaginal delivery. Obstet Gynecol 1982; 60: 664-6.

6. Kauppi-Sahla M, Rintala H, Makinen J. Bilateral tubal pregnancy: a case report and review of the literature. Eur J Obstet Gynecol Reprod Biol 1991; 40:145-7.
7. Lopez F, Muelas M, de Agustin P. Embarazo tubarico bilateral. Presentación de un caso. Acta Obstet Gin Hisp Lusit 1979; 27:423-7.

8. De Mello MAA. Prenhez ectópica considerações gerais e novas perspectivas terapêuticas. GO Atual 1995; 4:13-29.

9. Norris S. Bilateral simultaneous tubal pregnancy. Can Med Assoc J 1953; 68:379-81.

10.Olsen ME. Bilateral twin ectopic gestation with intraligamentous and interstitial components. A case report. J Reprod Med 1994; 39: 118-20.

11.Pezzani M. A case of simultaneous interstitial bilateral pregnancy. Acta Genet Med Gemellol 1976; 35:325-7.

12.Robertson WH. A bilateral fallopian tube pregnancy: case report. Fertil Steril 1980; 33: 86-7.

13.Sherman SJ. Werner M, Husain M. Bilateral ectopic gestations. Int J Gynaecol Obstet 1991; 35: 255-7. 